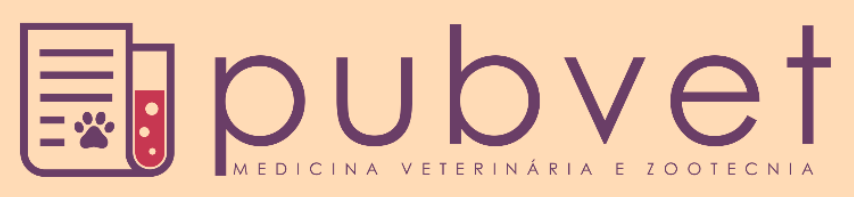

https://doi.org/10.31533/pubvet.v14n7a615.1-6

\title{
Caracterização do manejo e condutor de equídeos de carroça na área urbana de São Luís, Maranhão
}

\author{
Steyce Neves Barbosa ${ }^{1^{*}}$, Diego Luiz dos Santos Ribeiro ${ }^{20} \mathbb{D}^{\circ}$, Raquel da Silva Lima ${ }^{30}$, \\ Claudenilde de Jesus Pinheiro $\operatorname{Costa}^{30}$, Tielle da Luz Tavares ${ }^{4} \bullet$ \\ ${ }^{1}$ Doutoranda em Ciência animal- UNIVASF. Petrolina-PE Brasil. \\ ${ }^{2} M s c$., médico veterinário. São Luís, $M A$ \\ ${ }^{3}$ Programa de pós-graduação em Ciência animal e Pastagens, UFRPE/UAG \\ ${ }^{4}$ Secretaria municipal de agricultura familiar e meio ambiente, Bacuri, MA, Brasil. \\ *Autor para correspondência: E-mail: steyce.zoo@gmail.com
}

Resumo. O objetivo desta pesquisa foi caracterizar o manejo e o condutor de equídeos de carroça na área urbana de São Luís, Maranhão. Fez-se um levantamento socioeconômico do carroceiro bem como uma avaliação do manejo reprodutivo, sanitário e alimentar dos equídeos de tração, com base nisso fazendo uma analise do seu estado de bem-estar e orientando os proprietários destes animais. A metodologia utilizada para obtenção dos dados foi entrevista com aplicação de questionários, estes dados foram processados no Microsoft Office Excel 2010 sendo apresentado em porcentagens. Todos os entrevistados afirmaram ter renda de até 1 salário, com a maioria do ensino fundamental incompleto (57\%), com idade entre 19 e mais de 41 anos, 87\% dos motoristas eram de São Luís e 13\% de outras cidades. Todos os entrevistados afirmaram usar chicote, mas acrescentando que não para atingir o animal. Em relação à carga média utilizada para 69\% afirmaram $101 \mathrm{a}$ $450 \mathrm{~kg}, 9 \%$ acima de $451 \mathrm{~kg}$ e $22 \%$ não responderam. A atividade que utiliza equídeos para tração é desenvolvida por uma classe menos favorecida, sendo esta a principal ou única fonte de renda dos entrevistados. Há a necessidade de orientação e conscientização dos carroceiros, para que seja ampliada a qualidade de vida do animal, pois assim ambos serão favorecidos.

Palavras chave: burro, cavalo, carroceiro, jumento

\section{Characterization of the management and driver of wagon equine in the urban area of São Luís, Maranhão}

\footnotetext{
Abstract. The objective of this research was to characterize the handling and the driver of wagon equine in the urban area of São Luís, Maranhão. A socioeconomic survey of the driver was carried out, as well as an evaluation of the reproductive, sanitary and feeding management of the traction equines, based on therein doing an analysis of their welfare state and guiding the owners of these animals. The methodology used to obtain the data was interviewed with questionnaires, these data were processed in Microsoft Office Excel 2010 and presented in percentages. All respondents stated that they had an income of up to 1 salary, with the majority of elementary education incomplete (57\%), aged between 19 and over 41 years, $87 \%$ of the drivers were from São Luís and 13\% from other cities. All respondents claimed to use a whip, but adding that they did not target the animal. Regarding the average load used for $69 \%$, they stated 101 to $450 \mathrm{~kg}, 9 \%$ over $451 \mathrm{~kg}$ and $22 \%$ did not respond. The activity that uses Equidae for traction is developed by a less favored class, being this the main or only source of income of the interviewees. There is a need for
} 
guidance and awareness of the carters, so that the quality of life of the animal is increased, as thus both will be favored.

Keywords: carter, donkey, dumb, horse

\title{
Caracterización del manejo y conductor de équidos de carrosas en el área urbana de São Luís, Maranhão
}

\begin{abstract}
Resumen. El objetivo de esta investigación fue caracterizar el manejo y el conductor de los caballos carromatos en el área urbana de São Luís, Maranhão. Se realizó una encuesta socioeconómica del conductor, así como una evaluación del manejo reproductivo, sanitario y de alimentación de los equinos de tracción, basado en análisis de su estado de bienestar y guiando a los dueños de estos animales. La metodología utilizada para obtener los datos se entrevistó con cuestionarios, estos datos se procesaron en Microsoft Office Excel 2010 y se presentaron en porcentajes. Todos los encuestados declararon que tenían un ingreso de hasta 1 salario, con la mayoría de la educación primaria incompleta (57\%), con edades entre 19 y mayores de 41 años, el 87\% de los conductores eran de São Luís y el 13\% de otras ciudades. Todos los encuestados afirmaron usar un látigo, pero agregaron que no apuntaron al animal. Con respecto a la carga promedio utilizada para el 69\%, declararon $101 \mathrm{a} 450 \mathrm{~kg}, 9 \%$ sobre $451 \mathrm{~kg}$ y $22 \%$ no respondieron. La actividad que utiliza los équidos para la tracción es desarrollada por una clase menos favorecida, siendo esta la principal o única fuente de ingresos de los entrevistados. Existe la necesidad de orientación y concientización de los conductores, de modo que se incremente la calidad de vida del animal, ya que de esta manera se favorecerá a ambos.
\end{abstract}

Palabras clave: asno, burro, caballo, carretero

\section{Introdução}

Os equídeos são historicamente utilizados para tração. Sendo esta atividade desenvolvida pela categoria de subsistência de baixa renda que se utiliza dos animais para a execução de trabalhos com baixa remuneração. Os equídeos de tração desde a domesticação são tidos como ferramenta indispensável, utilizados para diversos trabalhos, geralmente exigidos acima de seus limites naturais (Maranhão et al., 2006).

No Brasil, os carroceiros representam uma categoria de trabalhadores que compõe o mercado informal, exercendo suas atividades em centros urbanos das diferentes regiões do país (Barbosa et al., 2011). Em todo o Brasil, animais destinados à atividade de tração para o transporte de materiais recicláveis coletados e material de construção por toda a cidade, constituem muitas vezes, a principal fonte de renda de seus proprietários (Rezende et al., 2004). Todavia, estes animais realizam tarefas árduas e exaustivas, na maioria das vezes vítimas de maus tratos devido à sobrecarga e aos horários prolongados de trabalho a que são submetidos, condição intensificada pelo clima tropical. Normalmente, quando fraquejam, são açoitados em locais que causam grande dor (SPAD, 2009).

O número de carroceiros e equídeo de tração circulante em São Luís é significante. Não havendo consciência por parte dos condutores e proprietários de carroças sobre a necessidade de um manejo sanitário e profilático dos seus animais. Assim, os equídeos são colocados em risco, bem como a população. Diante disto, a presente pesquisa objetivou avaliar o manejo nutricional, sanitário e reprodutivo de equídeos de tração na área urbana de São Luís, Maranhão, associados às condições de bem-estar do animal. Além disso, avaliar as condições socioeconômicas dos carroceiros da região, realizando, ao final, uma orientação técnica quanto ao manejo dos animais.

\section{Material e métodos}

A presente pesquisa foi realizada por meio de entrevistas com aplicação de questionário e conversa pessoal com carroceiros na área urbana de São Luís, para obtenção de dados sobre perfil do proprietário, manejo reprodutivo, manejo sanitário, e manejo alimentar dos equídeos. Totalizando 23 entrevistados. Os entrevistados encontravam-se em depósitos, praças, feiras, lojas de materiais de construção em 
bairros: São Bernardo, Vila Brasil, Ipem São Cristovão, Camboa, Liberdade e São Raimundo. Quanto à análise dos dados, as respostas dos questionários foram reunidas e, mediante o somatório dos dados totais das respostas apresentam-se seus dados elaborados no programa Microsoft Office Excel 2010. O bem-estar animal foi analisado a partir das respostas sobre o manejo dado aos equídeos e observação realizada no momento, bem como conversa com os proprietários. Ao final da entrevista, os carroceiros foram orientados sobre o manejo nutricional, sanitário e reprodutivo e como estes interferem no bemestar animal.

\section{Resultados e discussão}

Com a análise dos dados obtidos, verificou-se que $87 \%$ dos carroceiros tinham origem em São Luís e $13 \%$ de outras cidades do Maranhão. Todos eram do sexo masculino, com renda mensal de até um salário mínimo que beneficia, na maioria das vezes, quatro pessoas ou mais. Os materiais transportados pelos carroceiros eram, principalmente, materiais de construção e/ou entulho. Dos entrevistados, 87\% não exerce outro tipo de serviço para complementar a renda, contra apenas $13 \%$ que exerce. Em relação à idade, $13 \%$ dos participantes se enquadravam na faixa etária de 19 a 25 anos, $30 \%$ na faixa etária de 26 a 40 anos e 57\% acima de 41 anos. Quanto a escolaridade, 13\% não eram alfabetizados, 30\% tinham o ensino fundamental completo e $57 \%$ o fundamental incompleto. Conforme Almeida \& Silva (2010), os brasileiros que utilizam os equídeos como animais de tração são normalmente de poucas condições sociais e, com pouca instrução, transportam entulhos ou material de construção e realizam os serviços fretados para a obtenção de renda das famílias nos centros urbanos. Quanto à idade que ingressou na atividade, a maioria dos entrevistados $(91,3 \%)$ começou a trabalhar antes de atingir a maioridade. Kadani et al.(2014) trabalhando o perfil dos carroceiros, avaliação clínica e do bem-estar dos seus cavalos de tração da região de Pirassununga-SP verificaram que os entrevistados eram predominantemente homens e que a maioria dos entrevistados (15/26) começou a trabalhar antes de atingir a maioridade. Dos motivos que levaram os carroceiros a ingressarem na atividade, para a maioria a necessidade financeira foi o motivo principal $(60,8 \%)$.

A falta de regulamentação e de fiscalização por parte do governo, além da falta de oportunidades de outros serviços mais rentáveis, levou carroceiros a entrarem bem cedo na atividade (Fonteque et al., 2010; Kadani et al., 2014). Sobre o aprendizado da profissão, 52\% aprenderam a profissão de carroceiro por experiência própria, $31 \%$ aprenderam com a família e apenas $17 \%$ com amigos. Essa realidade é parecida com a encontrada em Uberlândia, onde Oliveira et al. (2007) constataram que o aprendizado sobre equinos é passado de pai para filho (47\%), apreendido com outros membros da família (10\%), adquirido com amigos (23\%), com a própria experiência (17\%) e/ou tendo trabalhado em fazendas $(23 \%)$.

Das espécies de equídeo que os entrevistados possuem: jumentos (11), cavalos (9), mulas (8), sendo que $78 \%$ vivem no quintal e $22 \%$ em terreno próximo. Dos carroceiros, $74 \%$ já tiveram animais roubados e não recuperaram e $26 \%$ não tiveram.

Quanto à carga horária de trabalho, 52\% afirmam ser de 9 horas ou mais e 48\% de 7-8 horas (11/23). De acordo com Segat et al. (2016), a carga horária de trabalho máxima para equinos de tração deveria ser de 8 horas por dia. Sobre o fato de dividir serviços entre os animais, $65 \%$ afirmam que dividem e $35 \%$ que não. Vale destacar que esses que não dividem serviço entre os animais possuem apenas um único equídeo. Em relação aos dias de trabalho, 39\% afirmam ser até quatro dias e $61 \%$ cinco dias ou mais. Todos os entrevistados afirmaram utilizar chicote; porém, acrescentando que não a fim de bater no animal. Com relação a carga média empregada ao animal, 69\% afirmaram ser de 101 a $450 \mathrm{~kg}$, 9\% acima de $451 \mathrm{~kg}$ e $22 \%$ não responderam. Segundo Oliveira et al. (2007) em uma pesquisa realizada junto aos carroceiros de Uberlândia/MG, observaram que a carga carregada pelos equídeos varia entre 500 e $800 \mathrm{~kg}$, acrescidos do peso da carroça (cerca de $150 \mathrm{~kg}$ ) e do carroceiro. O tipo e o tamanho do animal quanto à carga são levados em consideração pelo carroceiro segundo afirmaram. Segundo Segat et al. (2016) o peso transportado por equídeos na relação carga e porte animal deve estar entre 100 e 199 $\mathrm{kg}$ e conforme, Jordão et al. (2011) gira entorno de $100-150 \mathrm{~kg}$. De acordo com o vídeo documentário "Vida de Cavalo" (2005) um equídeo, para manter sua saúde adequada, deveria trabalhar cinco horas diárias. Desta forma, os carroceiros não estabelecem por si próprios, um horário para seus equídeos descansarem; só há descanso se não houver trabalho, o que torna essa atividade exaustiva. 
Os equídeos dos entrevistados nesta pesquisa estão sendo dispostos à sobrecarga que afeta seu bemestar animal e sua liberdade livre de estresse e de condições que possam vir a causar danos físicos aos mesmos. Vale destacar que nenhum dos animais observados demonstrava ferimentos ou sinais de maus tratos visíveis no momento da pesquisa. Dos animais, $62 \%$ eram fêmeas e $38 \%$ machos.

Quanto à monta natural, a maioria dos participantes utiliza animais emprestados para realizá-la. Dos entrevistados $87 \%$ afirmaram não fazer cruzamento entre animais de raças diferentes e também não escolhem animais específicos para cruzamento. E quanto a ter conhecimento sobre tempo de gestação da fêmea, $91 \%$ afirmaram que sim e $9 \%$ não conhecem. Dos que afirmaram conhecer responderam ainda ser ente 10-12 meses. Os equídeos devem ser selecionados para uma vida reprodutiva, e o tipo dele deve ser levado em consideração para que se possam ter cuidados específicos quanto ao tipo e à categoria animal.

Dos animais, $65 \%$ já foram vacinados e $35 \%$ não. É importante vacinar o animal assim que chegar à idade, pois isto além de fazer parte do bem-estar e da liberdade sanitária faz parte de um cuidado para evitar perdas econômicas por parte dos carroceiros já que a falta de alguma vacina pode levar o animal à morte. Dos que afirmaram vacinar disseram ainda ter sido apenas uma vez. Esse resultado é bastante diferente do que Oliveira et al. (2007) encontraram em Uberlândia, onde 63\% dos entrevistados nunca vacinaram seus equídeos e os demais (37\%), sim.

Dos entrevistados $30 \%$ afirmaram realizar e $70 \%$ não realizam ferrageamento do animal. Em relação à presença de cólicas $87 \%$ afirmam que o animal não apresenta e $13 \%$ sim; porém, raramente. Tridente (2011) ressalta que o casqueamento e ferrageamento não afetam somente a parte externa do casco, mas também suas estruturas internas, bem como influenciam as estruturas proximais do membro. Muitos médicos veterinários e ferradores afirmam que uma grande proporção dos casos de claudicação pode ser evitada ou tratada, utilizando-se somente prática de ferrageamento adequada.

Dos animais, $43 \%$ já receberam anti-helmíntico e 57\% não. Quanto à vermifugação 43\%, afirmam que o animal não é vermifugado e $57 \%$ que sim. Dos animais $70 \%$ não é pulverizado e $30 \%$ é. Quando perguntados se o animal já apresentou algum tipo de enfermidade, $83 \%$ disseram que não e $17 \%$ sim. Perguntou-se também se já haviam tido problemas com carrapatos, $70 \%$ não e $30 \%$ sim, destes que responderam sim, disseram que utilizaram pasta, sal e barragem para combater. É indicada uma rotina de aplicação de vermífugos de tempos em tempos. Os intervalos entre as aplicações irão variar de acordo com o princípio ativo e a posologia do medicamento. Os principais ectoparasitas considerados importantes dentro de um bom manejo sanitário são os carrapatos que devem ser combatidos por carrapaticidas tanto no ambiente quanto no animal (Rocha et al., 1984).

Os carroceiros que afirmaram vermifugar na presente pesquisa e disseram ainda ser eventualmente, o que, de acordo com a literatura (Canal et al., 2004; Duarte et al., 2008), não é suficiente para manter níveis baixos de infestação por endoparasitos, quando o ideal seria ao menos quatro vezes ao ano para indivíduos adultos. Dos 23 carroceiros, apenas 11 afirmam já ter procurado orientação técnica sobre controle e prevenção de verminoses. Conforme Souza (2006), por falta de recursos de seus proprietários, equinos de tração recebem muito pouca ou nenhuma assistência médica, tanto preventiva quanto curativa, tal como vacinação, vermifugação e tratamento para doenças e ferimentos e a autora ainda complementa que programas de assistência a equinos de tração que têm sido realizados como projetos até mesmo por estudantes, pode ser uma forma eficiente de minimizar os problemas de saúde desses animais, ao mesmo tempo em que beneficia a sociedade. Somado a condição destes carroceiros, há falta de políticas públicas para promoção do bem-estar animal, dando capacitação a estes profissionais quanto ao manejo sanitário dos equídeos.

Dos alimentos oferecidos aos equídeos, predomina o uso de forragem e concentrado $(78,2)$. No caso da forragem oferecida foram citadas, capim cana, colonião e capim baixo. Todos afirmaram não haver um balanceamento dessa alimentação. A escolha dos alimentos se dá por: qualidade (22\%), preço (30\%) e disponibilidade (48\%). A maioria dos carroceiros afirmou que o equídeo nunca apresentou problema alimentar $(95,6)$. O concentrado deve ser considerado como complemento do volumoso e não o inverso. Caso a quantidade de concentrado não seja suficiente para o equino desempenhar a função desejada, deve-se utilizar ração mais energética, além do fornecimento de volumoso, evitando dessa maneira a sobrecarga e sobrepeso do trato gastrointestinal (Cintra, 2011; Lewis, 2000; Primiano, 2010). Quanto à 
frequência diária de alimentação, $8 \%$ oferecem o alimento ao animal uma vez ao dia e $92 \%$ duas vezes. A quantidade diária ofertada a equídeo é de: quantidade variável (35\%), 22\% até $5 \mathrm{~kg}, 26 \%$ acima de 5 $\mathrm{kg} \mathrm{e} 17 \%$ não souberam responder, sendo esta quantidade definida por idade (13\%), condição fisiológica (17\%), tamanho (31\%) e 39\% nenhum critério de definição fixo, citando ainda ser por observação e à medida que vão colocando, se o animal for comendo e aparentar querer mais eles aumentam a quantidade. Assim como a frequência, a quantidade de nutrientes fornecidos é muito importante, pois, deve ser capaz de manter os equídeos com escore corporal ideal para realização do trabalho (Cintra, 2011).

Em relação à água, $100 \%$ dos carroceiros afirmaram ser à vontade em bebedouros como tanques e baldes. Quanto à origem dessa água, é predominantemente de poços artesianos (86\%). Todos os entrevistados afirmaram durante intervalos, fornecer água e sombra ao equídeo e não os soltar dos arreios. Oferta de água e sombra durante intervalos é fundamental para o bem-estar do equídeo de tração e diz respeito ao atendimento de mais uma liberdade que deve ser cumprida. Esses resultados também foram encontrados por Kadani et al. (2014) em pesquisa já mencionada neste trabalho, onde todos os carroceiros responderam positivamente a pergunta relacionada ao fornecimento de sombra e água fresca aos seus animais durante os intervalos de serviço, embora muitos não soltassem os arreios de seus animais durante o descanso. Heleski et al. (2002) recomendam que nos períodos de descanso os animais devam ser soltos e escovados; o que contribui para a prevenção do aparecimento de lesões cutâneas.

\section{Conclusão}

Quanto ao manejo, notou-se que embora com dificuldades e algumas irregularidades, os carroceiros tentam oferecer boa condição de vida aos equídeos para que suas liberdades sejam respeitadas.

Mesmo que não tecnicamente, os carroceiros têm noções sobre bem-estar, e alguns cuidados quanto ao manejo reprodutivo, sanitário e alimentar.

Quanto aos que não possuem conhecimento, percebe-se a necessidade de orientação e conscientização dos carroceiros, para que seja ampliada a qualidade de vida do animal, pois assim ambos serão favorecidos.

\section{Referências bibliográficas}

Almeida, F. Q., \& Silva, V. P. (2010). Progresso científico em equideocultura na 1a década do século XXI. Revista Brasileira de Zootecnia, 39, 119-129. https://doi.org/10.1590/S151635982010001300014

Barbosa, L. D., Santos, M. A. M., Batista, P. V. M., Moura, J. B., Vieira, D. S., Gradela, A., Faria, M. D., Horta, M. C., \& Milken, V. M. F. (2011). Aspectos pedagógicos e didáticos do" Projeto Carroceiro" no município de Petrolina: bem estar de equídeos e preocupação social. Revista Conexão, 7(2), 260-265.

Canal, I. H., Canal, R. B., \& Didiano, J. M. (2004). LEVAMISOL vermífugo e imuno modulador: antigo e eficaz. Uma revisão bibliográfica e indicações de uso. Revista Electrónica de Veterinária, 5(6), $1695-7504$.

Cintra, A. G. C. (2011). O cavalo: características, manejo e alimentação. Roca.

Duarte, E. R., Oliveira, N. J. F., Silveira, J. T., Ribeiro, F. L. A., \& Souza, R. M. (2008). Controle de verminose em equinos no norte de Minas Gerais com associação de pamoato de pirantel e ivermectina. Revista Caatinga, 21(1), 1-4.

Fonteque, J. H., Paolini, E., \& Silva, M. C. (2010). Programa amigo do carroceiro. Cidadania Em Ação: Revista de Extensão e Cultura, 4(1), 1-6.

Heleski, C. R., Shelle, A. C., Nielsen, B. D., \& Zanella, A. J. (2002). Influence of housing on weanling horse behavior and subsequent welfare. Applied Animal Behaviour Science, 78(2-4), 291-302. https://doi.org/10.1016/s0168-1591(02)00108-9

Jordão, L. R., Faleiros, R. R., \& Aquino Neto, H. M. (2011). Animais de trabalho e aspectos éticos envolvidos: revisão crítica. Acta Veterinaria Brasilica, 5(1), 33-40.

Kadani, M. Y., Dória, R. G. S., \& Gameiro, A. H. (2014). Perfil dos carroceiros, avaliação clínica e do 
bem-estar dos seus cavalos de tração da região de Pirassununga-SP. Revista de Educação Continuada Em Medicina Veterinária e Zootecnia Do CRMV-SP, 12(3), 6-11. https://doi.org/10.36440/recmvZ.v12i3.24622

Lewis, L. D. (2000). Nutrição clínica eqüina: alimentação e cuidados. Roca.

Maranhão, R. P. A., Palhares, M. S., Melo, U. P., Rezende, H. H. C., Braga, C. E., Silva Filho, J. M., \& Vasconcelos, M. N. F. (2006). Afecções mais freqüentes do aparelho locomotor dos eqüídeos de tração no município de Belo Horizonte. Arquivo Brasileiro de Medicina Veterinária e Zootecnia, 58(1), 21-27. https://doi.org/10.1590/s0102-09352006000100004

Oliveira, L. M., Marques, R. L., Nunes, C. H., \& Cunha, A. M. O. (2007). Carroceiros e equídeos de tração: um problema sócio-ambiental. Caminhos de Geografia, 8(24), 204-216.

Primiano, F. M. (2010). Manejo e nutrição do cavalo atleta. Revista Cães \& Gatos, 11, 16-18.

Rezende, H. H. C., Palhares, M. S., Aguiar, E. G., Silva, R. H. A., \& Pereira, M. S. N. (2004). Impacto da migração dos carroceiros de Belo Horizonte: setor formal para o setor informal. VII Encontro de Extensão Da Universidade Federal de Minas Gerais Belo Horizonte, 1-6.

Rocha, U. F., Banzatto, D. A., Woelz, C. R., Bechara, G. H., Galluzzi, F. D., \& Garcia, M. C. C. (1984). Ecologia de carrapatos VII - a escassa influência da luz do dia sobre oviposição e embriogênese de Boophilus microplus (Canestrini); equivalência de contagens de larvas e de cascas d'ovos. Semina: Ciências Agrárias, 5(16), 5-14. https://doi.org/10.5433/1679-0359.1984v5n16p5

Segat, H. J., Braga, D. N., Samoel, G. V. A., Porto, I. P., Weiblen, C., Rodrigues, F. S., Vogel, F. S. F., Pereira, D. I. B., Sangioni, L. A., \& Botton, S. A. (2016). Equino de tração de carroças: interação social e bem estar animal. Investigação, 15(4).

Souza, M. F. A. (2006). Implicações para o bem estar de equinos usados para tração de veículos. Revista Brasileira de Direito Animal, 1, 191-198. https://doi.org/10.9771/rbda.v1i1.10247

SPAD, Sociedade protetora dos animais de Divinopólis. Animais de tração. Disponível em: http://www.spad.org.br/ler_noticia.php?id_noticia=109. Acesso em 15 de Maio de 2016.

Tridente, M. F. (2011). Importância do casqueamento e ferrageamento no cavalo atleta. Universidade Estadual Paulista (UNESP).

Recebido: 10 de fevereiro, 2020 .

Aprovado: 16 de março, 2020.

Disponível online: 31 julho, 2020.

Licenciamento: Este artigo é publicado na modalidade Acesso Aberto sob a licença Creative Commons Atribuição 4.0 (CC-BY 4.0), a qual permite uso irrestrito, distribuição, reprodução em qualquer meio, desde que o autor e a fonte sejam devidamente creditados. 